\title{
Effect of Repeated Tempering on Abrasive Wear Behavior of Hypoeutectic 16 mass\% Cr Cast Iron with Molybdenum
}

\author{
Sudsakorn Inthidech ${ }^{1, *}$, Pisizchai Kosasu ${ }^{1}$, Sumpao Yotee $^{1}$ and Yasuhiro Matsubara ${ }^{2}$ \\ ${ }^{1}$ Department of Manufacturing Engineering, Mahasarakham University, Mahasarakham, Thailand \\ ${ }^{2}$ Department of Materials Science and Engineering, Kurume National College of Technology, Kurume 830-8555, Japan
}

\begin{abstract}
The effects of hardness, volume fraction of retained austenite $\left(V_{\gamma}\right)$ and the number of tempering $\left(t_{\mathrm{N}}\right)$ on abrasive wear resistance of hypoeutectic 16 mass $\% \mathrm{Cr}$ cast irons without and with Mo was investigated. After annealing, the specimens were austenitized at $1323 \mathrm{~K}$ for $5.4 \mathrm{ks}$ and cooled by fan air cooling. The hardened specimen was repeatedly tempered, at most three times at $748-798 \mathrm{~K}$ for $7.2 \mathrm{ks}$. The abrasive wear resistance of heat-treated specimens was evaluated using a Suga wear tester (two-body-type abrasive test). In the as-hardened state, the hardness did not change but the $V_{\gamma}$ increased gradually with an increase in the Mo content. In the tempered state, the hardness curves showed a secondary hardening as the $t_{\mathrm{N}}$ increased due to the precipitation of secondary carbides and transformation of destabilized austenite to martensite. The wear loss increased in proportion to the wear distance in all specimens. The wear rate $\left(R_{\mathrm{W}}\right)$ varied depending on the $t_{\mathrm{N}}$ and Mo content. The $R_{\mathrm{W}}$ decreased when the hardness was increased. The $R_{\mathrm{W}}$ increased first and then decreased as the $t_{\mathrm{N}}$ increased. The highest wear resistance was obtained in the $3 \%$ Mo cast iron with triple tempering. [doi:10.2320/matertrans.M2012185]
\end{abstract}

(Received May 17, 2012; Accepted October 5, 2012; Published November 16, 2012)

Keywords: high chromium cast iron, repeated tempering, abrasive wear resistance, hardness, volume fraction of retained austenite

\section{Introduction}

High chromium cast iron has been applied to abrasive wear resistant materials for more than 50 years. It has been commonly used for rolling mill rolls in steel plants, liners, rollers and tables for pulverizing mills in the mining and cement industries because of its high abrasive wear and corrosion resistances. In general, the commercial grade of high chromium cast iron contains $12-30$ mass $\%$ (hereafter shown by \%) $\mathrm{Cr}$ and $2.0-3.6 \% \mathrm{C}$. The other elements like molybdenum $(\mathrm{Mo})$, manganese $(\mathrm{Mn})$, copper $(\mathrm{Cu})$ and nickel (Ni) are usually added to prevent pearlite transformation during solidification and to improve the hardenability.

The high wear performance of high chromium cast iron depends on both the amount and type of eutectic carbide and the matrix structure. ${ }^{1-5)}$ Several papers reported that the wear resistance increased with increasing the volume fraction of eutectic carbide in the abrasive wear. ${ }^{1-4)}$ However, a large volume fraction of eutectic carbide deteriorates the toughness and therefore, it is undesirable when the high chromium cast iron is used for construction components. ${ }^{1,3)}$ In order to get higher toughness, the volume fraction of eutectic carbide must be limited and especially, the precipitation of coarse primary carbides should be avoided. Hence, the high chromium cast iron with hypoeutectic composition has been preferentially used.

In the two-body type abrasive wear process, the wear takes place when the hard angular abrasive particles contact the wear surface, e.g., hammer and liner of impact crusher. The local stresses between abrasive particles and wear surface are high enough to crush the stones and minerals, leading to heavy plastic deformation on the wear surface. Therefore, the high surface hardness and appropriate toughness are required. In order to evaluate the two-body type abrasive wear resistance, an abrasive paper, on which surface very hard

*Corresponding author, E-mail: sudsakorn.i@msu.ac.th abrasive particles such as $\mathrm{SiC}$ or $\mathrm{Al}_{2} \mathrm{O}_{3}$ are bonded by glue, is generally used. The Suga wear tester is suitable to evaluate the abrasive wear resistance of two-body-type. $\left.{ }^{6}\right)$

The heat treatment of high chromium cast iron has been studied by many researchers. ${ }^{1-4,6-14)}$ The abrasive wear resistance of high chromium cast iron with hardening and single tempering has been reported. ${ }^{1-4,6,7,11,14)}$ However, the research on wear behavior of high chromium cast iron subject to repeated tempering has not been found. In this study, therefore, the hypoeutectic $16 \% \mathrm{Cr}$ cast irons without and with Mo were prepared and heat-treated. Then, abrasive wear test was carried out using Suga wear tester (two-body-type abrasive test). The relationships between abrasive wear resistance, hardness, volume fraction of retained austenite $\left(V_{\gamma}\right)$, Mo content and number of tempering $\left(t_{\mathrm{N}}\right)$ were clarified.

\section{Experimental Procedures}

\subsection{Preparation of test specimens}

Hypoeutectic $16 \% \mathrm{Cr}$ cast irons with and without molybdenum were produced using a $30 \mathrm{~kg}$ capacity high frequency induction furnace with alumina lining. Raw materials such as mild steel, pig iron, ferro-alloys and pure metals were used as charge materials. The charge materials were melted down and superheated up to $1853 \mathrm{~K}$. After holding at the temperature, the melt was poured from temperature between 1793 and $1773 \mathrm{~K}$ into preheated $\mathrm{CO}_{2}$ bonded sand mould in Y-block shape. The mould consists of the cavity for specimen with the size of $50 \times 50 \times 200 \mathrm{~mm}$ and sufficient volume riser as shown in Fig. 1. The top surface of riser was immediately covered with dry exothermic powder to hold the melt temperature of riser high. The Y-block castings were sectioned by a wire-cutting machine to obtain test pieces with dimension of $50 \times 50 \times 7 \mathrm{~mm}$. The chemical compositions of test specimens are shown in Table 1. 

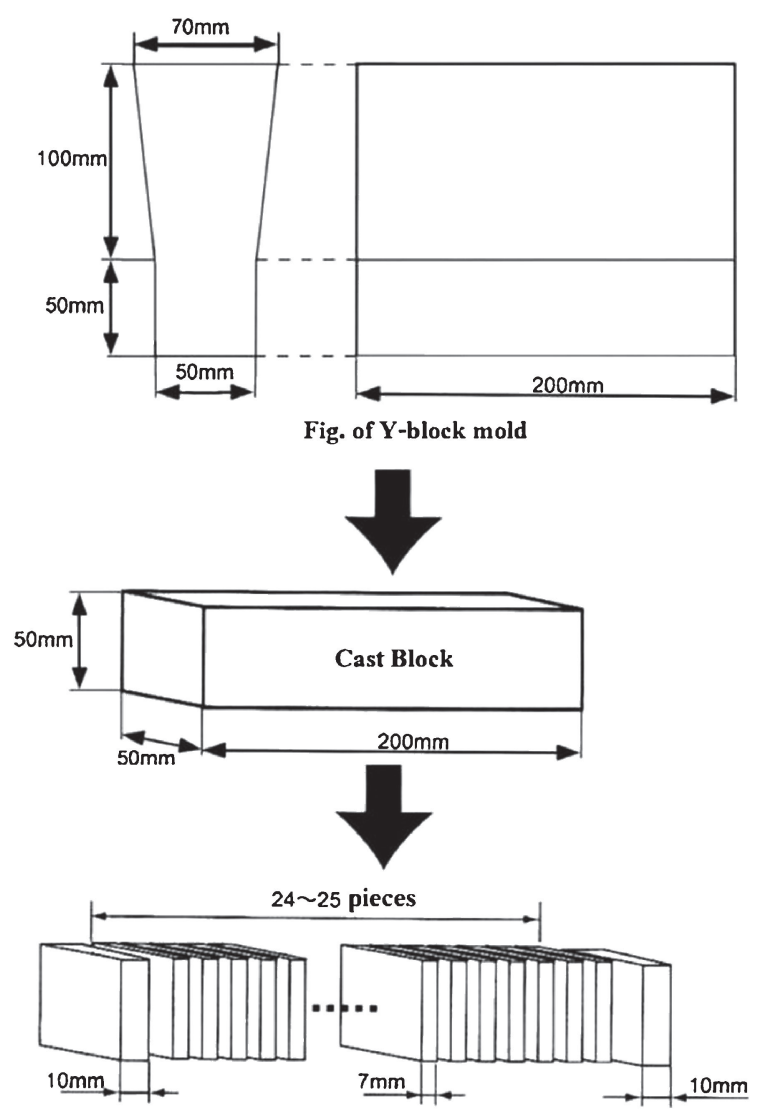

Fig. 1 Schematic drawings of procedure to produce test pieces.

Table 1 Chemical composition of test specimens.

\begin{tabular}{lccccc}
\hline \multirow{2}{*}{ Specimen } & \multicolumn{5}{c}{ Alloy (mass\%) } \\
\cline { 2 - 6 } & $\mathrm{C}$ & $\mathrm{Cr}$ & $\mathrm{Si}$ & $\mathrm{Mn}$ & Mo \\
\hline Mo-free & 2.96 & 15.93 & 0.51 & 0.55 & 0.22 \\
$1 \%$ Mo & 2.95 & 16.00 & 0.50 & 0.55 & 1.06 \\
$2 \%$ Mo & 2.97 & 15.96 & 0.54 & 0.59 & 1.95 \\
$3 \%$ Mo & 2.91 & 15.91 & 0.47 & 0.55 & 2.98 \\
\hline
\end{tabular}

\subsection{Heat treatment procedure}

After annealing at $1273 \mathrm{~K}$ for $18 \mathrm{ks}$, the test pieces were austenitized at $1323 \mathrm{~K}$ for $5.4 \mathrm{ks}$ and hardened by fan air cooling. The hardened test pieces were tempered at the temperatures between 748 and $798 \mathrm{~K}$ for $7.2 \mathrm{ks}$ for at most three times. The three tempering temperatures were determined referring to the tempering hardness curves obtained in the previous work. ${ }^{9)}$ After tempering, the test pieces were cooled to room temperature in the air.

\subsection{Measurement of hardness and volume fraction of retained austenite $\left(V_{\gamma}\right)$}

After grinding the surface of test piece by $\mathrm{SiC}$ papers down to 800-grit, the surface was polished with fine alumina powder. Then, test piece was light etched to reveal dendrite and eutectic structures. Measurement of macro-hardness was carried out by Vicker hardness tester with load of $294 \mathrm{~N}$ (30 kgf), and that of micro-hardness was carried out in the dendrite region using Micro-Vicker hardness tester with load of $0.98 \mathrm{~N}(0.1 \mathrm{kgf})$. More than five indents were taken at random and the average value was adopted.

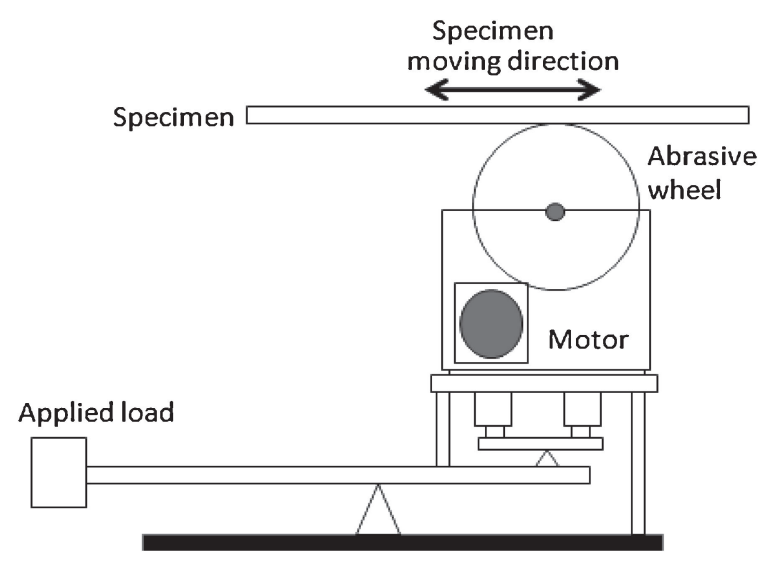

Fig. 2 Schematic drawing of Suga wear tester.

The $V_{\gamma}$ was obtained by X-ray diffraction method using a special goniometer with automatic rotating and swinging sample stage. ${ }^{8-13,15)}$ Mo-K $\alpha$ characteristic line with a wavelength of $0.0711 \mathrm{~nm}(0.711 \AA)$ filtered by $\mathrm{Zr}$ was used as the source of X-ray beam. The diffraction peaks used for $V_{\gamma}$ calculation were (200), (220) planes for ferrite $(\alpha)$ or martensite (M) and (220), (311) planes for austenite $\left.(\gamma){ }^{15}\right)$

\subsection{Observation of microstructure}

Microstructure of specimens was observed by an optical microscope $(\mathrm{OM})$ and a scanning electron microscope (SEM). Vilella's etchant was used to reveal microstructure. In the SEM investigation, the secondary electron image was taken using an accelerating voltage of $15 \mathrm{kV}$.

\subsection{Abrasive wear test}

The surface roughness of test pieces was controlled to be less than $1 \mu \mathrm{m}$ (R-max) using a grinding machine. A schematic drawing of Suga wear tester is illustrated in Fig. 2. A load of $9.8 \mathrm{~N}$ (1 kgf) was applied to the test piece by the abrading wheel with $44 \mathrm{~mm}$ in diameter and $12 \mathrm{~mm}$ in thickness. The wheel on which circumference was adhered by 180 mesh $\mathrm{SiC}$ abrasive paper moves back and forth on the same area of test piece for $30 \mathrm{~mm}$ distance. Simultaneously, the wheel rotated intermittently for 0.9 degrees per one stroke, that is, the rotation speed of wheel is $0.23 \mathrm{~mm} / \mathrm{s}$. Therefore, the total distance by one revolution or 360 degrees is $30 \times 2 \times 400 \mathrm{~mm}(24 \mathrm{~m})$. After finishing one test, the specimen was cleaned in an ultrasonic bath with acetone and then dried. Weight of the test piece was measured using a high precision digital weight balance with $0.1 \mathrm{mg}$ accuracy. The test was repeated eight times or until the total of wear distance reaches $192 \mathrm{~m}$ on a test piece.

\section{Results and Discussions}

\subsection{Characterization of test specimens}

The microphotographs of as-hardened specimens were taken by OM and SEM and they are representatively shown in Fig. 3. The matrix structure consists of comparatively large amount of fine carbides, martensite and some retained austenite. As Mo content increases, austenite or pearlite existed in the as-cast state is greatly reduced by holding at the hardening temperature, and instead, more carbide can be 


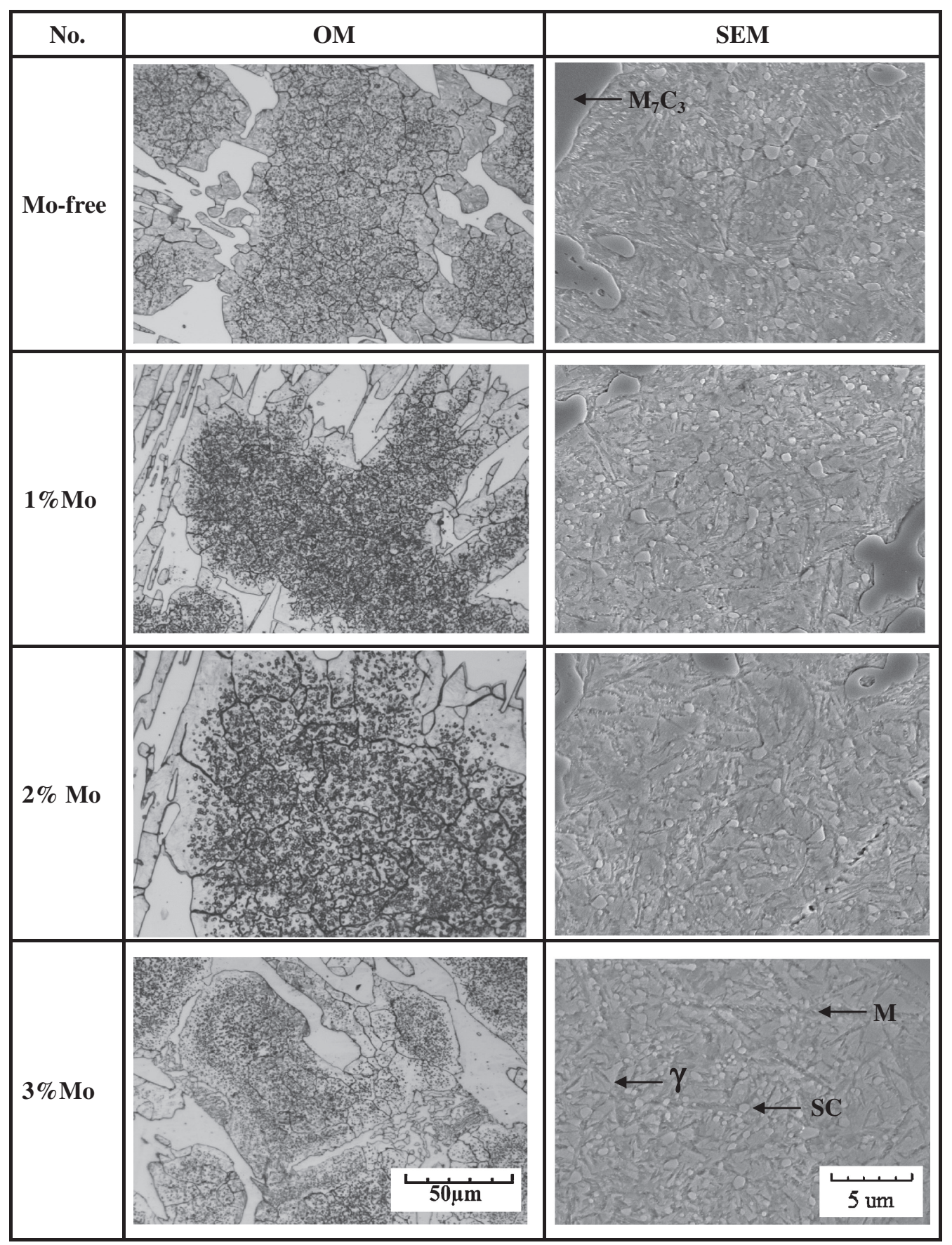

Fig. 3 As-hardened microstructures of test specimens observed by OM and SEM. (M: Martensite and SC: Secondary carbide)

observed. This proves that the decomposition of austenite occurred during destabilization or austenitization. It was reported that these secondary carbides are $\mathrm{M}_{23} \mathrm{C}_{6}$ and some $\mathrm{M}_{7} \mathrm{C}_{3} \cdot{ }^{1)}$ The eutectic carbide of $\mathrm{Mo}_{2} \mathrm{C}$ could be observed at the boundary region of dendrite in $3 \%$ Mo specimen. However, it is not found in the microphotograph.

Hardness and $V_{\gamma}$ of test pieces are summarized in Table 2. It is found that the hardness and $V_{\gamma}$ vary depending on Mo content and greatly on the $t_{\mathrm{N}}$. Effects of Mo content on the macro-hardness and $V_{\gamma}$ values of heat-treated specimens are shown in Figs. 4 and 5, respectively. The hardness in the as-hardened state decreases slightly as the Mo content is increased. However, it is higher than that in the tempered state except for the 3\%Mo-specimen treated by triple temperings. In the tempered state, the hardness increases with an increase in the Mo content and the $t_{\mathrm{N}}$ due to the precipitation of secondary carbides from austenite and transformation of retained austenite into martensite during cooling after tempering. The highest hardness is obtained in the triple tempered specimen with $3 \%$ Mo that contains largest amount of $V_{\gamma}$ in the as-hardened state. The hardness of the single tempered specimen is the lowest because the transformation of retained austenite to martensite is least. The degree of secondary hardening, which is defined as the difference in hardness between the single and triple tempering, increases as the Mo content rises. In Fig. 5, it is clear that the $V_{\gamma}$ in the as-hardened state is greater in Mo-containing specimens compared with Mo-free specimen. 
Table 2 Hardness and volume fraction of retained austenite $\left(V_{\gamma}\right)$ of specimens with different number of tempering $\left(t_{\mathrm{N}}\right)$.

\begin{tabular}{|c|c|c|c|c|}
\hline Specimen & Tempering condition & $\begin{array}{l}\text { Macro- } \\
\text { hardness } \\
\text { (HV30) }\end{array}$ & $\begin{array}{l}\text { Micro- } \\
\text { hardness } \\
(\mathrm{HV} 0.1)\end{array}$ & $\begin{array}{c}V_{\gamma} \\
(\%)\end{array}$ \\
\hline \multirow{4}{*}{ Mo-free } & As-hardened & $862 \pm 12$ & $719 \pm 22$ & 24 \\
\hline & Single tempering ( $748 \mathrm{~K})$ & $730 \pm 11$ & $633 \pm 18$ & 9 \\
\hline & Double tempering ( $748 \mathrm{~K})$ & $782 \pm 17$ & $646 \pm 16$ & 6 \\
\hline & Triple tempering ( $748 \mathrm{~K})$ & $804 \pm 10$ & $660 \pm 21$ & 1 \\
\hline \multirow{4}{*}{$1 \% \mathrm{Mo}$} & As-hardened & $860 \pm 13$ & $712 \pm 21$ & 35 \\
\hline & Single tempering $(748 \mathrm{~K})$ & $747 \pm 12$ & $634 \pm 18$ & 14 \\
\hline & Double tempering ( $748 \mathrm{~K})$ & $798 \pm 10$ & $651 \pm 19$ & 12 \\
\hline & Triple tempering $(748 \mathrm{~K})$ & $824 \pm 16$ & $670 \pm 13$ & 8 \\
\hline \multirow{4}{*}{$2 \% \mathrm{Mo}$} & As-hardened & $859 \pm 10$ & $710 \pm 16$ & 41 \\
\hline & Single tempering (798 K) & $754 \pm 17$ & $641 \pm 18$ & 15 \\
\hline & Double tempering (798 K) & $809 \pm 15$ & $660 \pm 13$ & 14 \\
\hline & Triple tempering $(798 \mathrm{~K})$ & $855 \pm 12$ & $714 \pm 14$ & 9 \\
\hline \multirow{4}{*}{$3 \% \mathrm{Mo}$} & As-hardened & $862 \pm 11$ & $715 \pm 14$ & 47 \\
\hline & Single tempering $(798 \mathrm{~K})$ & $769 \pm 13$ & $667 \pm 19$ & 22 \\
\hline & Double tempering ( $798 \mathrm{~K})$ & $855 \pm 14$ & $704 \pm 16$ & 16 \\
\hline & Triple tempering (798 K) & $895 \pm 11$ & $742 \pm 17$ & 10 \\
\hline
\end{tabular}

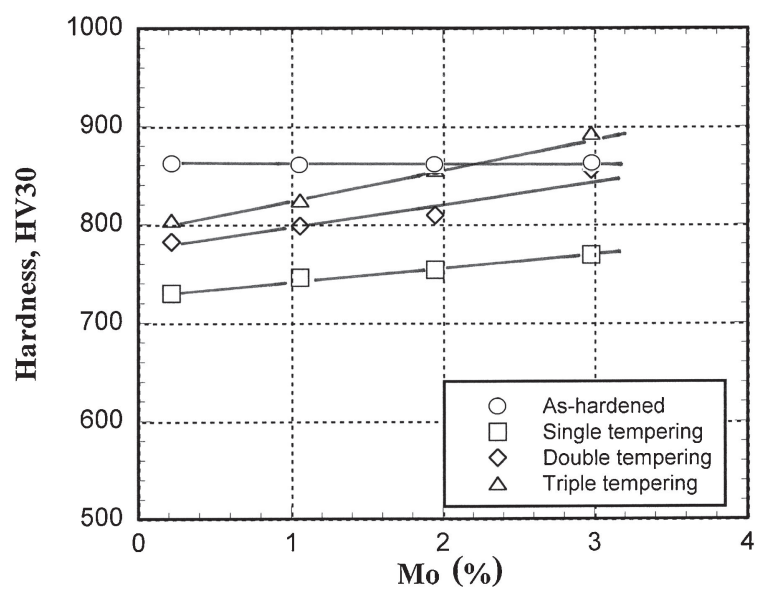

Fig. 4 Effect of Mo content on macro-hardness of heat-treated specimens.

This is because Mo not only shifts the pearlite transformation to the long time side and improves the hardenability but also stabilizes the austenite. The relations of $V_{\gamma}$ vs. $t_{\mathrm{N}}$ are shown in Fig. 6. The $V_{\gamma}$ decreases remarkably by the single tempering and then gradually lowers as the $t_{\mathrm{N}}$ is increased, regardless of Mo content, and the $V_{\gamma}$ of triple tempered specimen is smallest.

\subsection{Abrasive wear resistance}

The relationship between wear loss and wear distance of all the specimens is shown in Fig. 7. In all of the figures, the wear loss increases in proportion to the wear distance. Since the linear relations were obtained between wear loss and wear distance, the parameter of wear rate $\left(R_{\mathrm{w}}: \mathrm{mg} \cdot \mathrm{m}^{-1}\right)$, which is expressed by the slope of each straight line, is introduced. The total wear loss and $R_{\mathrm{w}}$ at $192 \mathrm{~m}$ wear test of specimens heat-treated by different conditions are summarized in Table 3. It is found that the $R_{\mathrm{w}}$ changes depending on the heat treatment condition and Mo content. The small $R_{\mathrm{w}}$ is

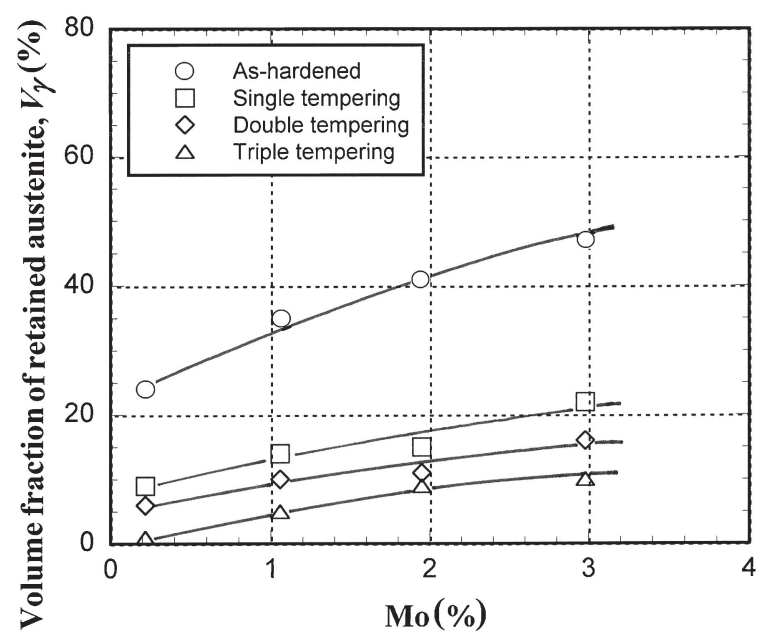

Fig. 5 Effect of Mo content on volume fraction of retained austenite $\left(V_{\gamma}\right)$ of heat-treated specimens.

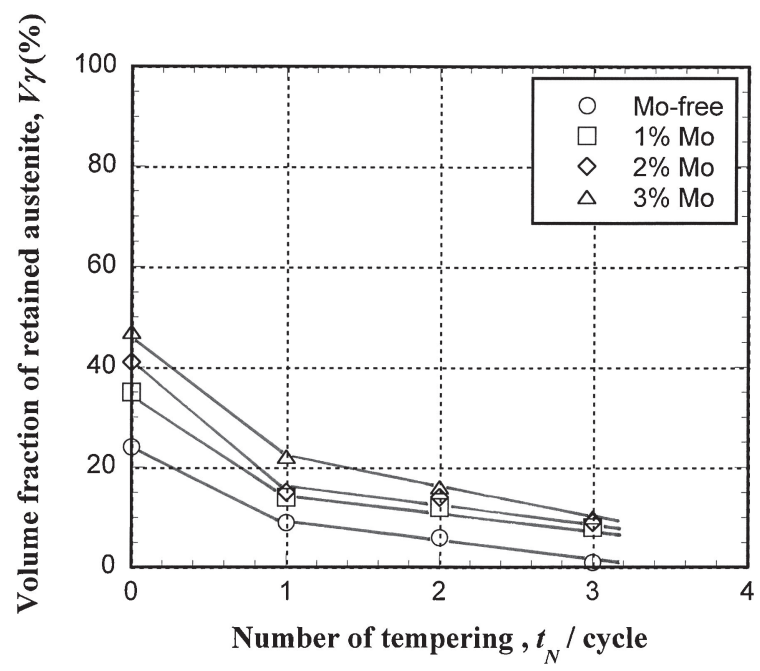

Fig. 6 Relationship between the volume fraction of retained austenite $\left(V_{\gamma}\right)$ and the number of tempering $\left(t_{\mathrm{N}}\right)$.

obtained in the as-hardened or the triple tempered specimens, the former is due to high carbon martensite with higher harness and the latter is due to martensite transformed from retained austenite and secondary carbides. The largest $R_{\mathrm{W}}$ is obtained in single tempered specimen where a large portion of austenite is still remained and very small amount of secondary carbides exists.

The relationship between $R_{\mathrm{W}}$ and macro-hardness is shown in Fig. 8 and the relations are expressed by the next equations,

As-hardened: $R_{\mathrm{w}}=-1.11 \times 10^{-3} \times \mathrm{HV} 30+1.42$

$$
\text { ( } R=0.71)
$$

Single tempering: $R_{\mathrm{w}}=-2.11 \times 10^{-3} \times \mathrm{HV} 30+2.09$

$$
(R=0.98)
$$

Double tempering: $R_{\mathrm{w}}=-2.28 \times 10^{-3} \times \mathrm{HV} 30+2.32$

$$
\text { ( } R=0.98)
$$

Triple tempering: $R_{\mathrm{w}}=-0.84 \times 10^{-3} \times \mathrm{HV} 30+0.52$

$$
(R=0.91)
$$



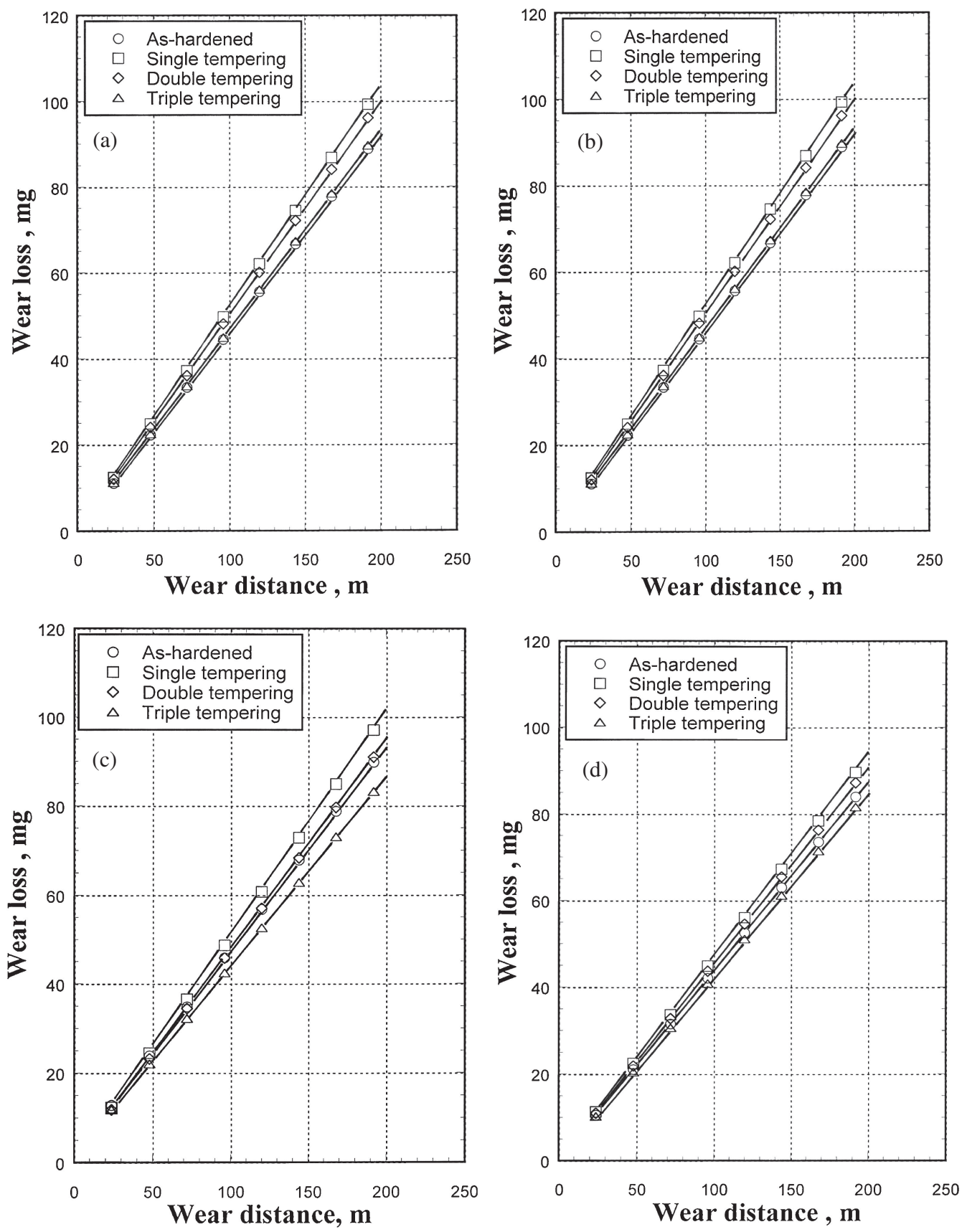

Fig. 7 Relationship between wear loss and wear distance of $16 \% \mathrm{Cr}$ cast iron without and with Mo. (a) Mo-free (b) $1 \%$ Mo (c) $2 \%$ Mo (d) $3 \%$ Mo.

As the macro-hardness increases, the $R_{\mathrm{w}}$ value decreases proportionally with an increase in the hardness if the $t_{\mathrm{N}}$ is the same. In other words, the higher macro-hardness provides better wear resistance. From Fig. 4, it was clarified that the hardness rose by increasing the $t_{\mathrm{N}}$ because the amount of martensite and precipitated carbides in the matrix increases. Under high stress wear condition, the martensite provides high abrasive wear resistance because the matrix is strengthened enough to prevent the eutectic carbides from fracturing. In addition, the secondary carbides increase the matrix strength through an effect of dispersion hardening, , $^{1,3}$ and this also leads to the improvement of the wear resistance.

It is also found in Fig. 8 that the relation of $R_{\mathrm{w}}$ Vs. hardness is closely related in the single tempering and the relation locates in the low hardness side, and it shifts to high hardness side as the $t_{\mathrm{N}}$ increases. This behavior should be affected by the different matrix microstructure which is determined by the $t_{\mathrm{N}}$. The increasing ratio of hardness in the double and triple tempered specimens is greater than that in the single tempered specimen. This can be explained that an increase of the $t_{\mathrm{N}}$ promoted the destabilization of austenite, the precipitation of $\mathrm{M}_{23} \mathrm{C}_{6}$ carbides as well as that of special carbides of $\mathrm{Mo}_{2} \mathrm{C}^{1,9,14)}$ in the case of specimens with Mo, and following martensite transformation from remaining austenite.

The amount of retained austenite also affects the wear resistance of high chromium cast iron. The relationship between $R_{\mathrm{w}}$ and $V_{\gamma}$ is shown in Fig. 9 separately for the number of tempering, and the relations are expressed as follows; 
Table 3 Total wear loss and wear rate $\left(R_{\mathrm{w}}\right)$ of test specimens.

\begin{tabular}{|c|c|c|c|}
\hline Specimen & $\begin{array}{l}\text { Tempering } \\
\text { condition }\end{array}$ & $\begin{array}{l}\text { Total wear loss } \\
\text { (at } 192 \mathrm{~m} \text { ), mg }\end{array}$ & $\begin{array}{c}\text { Wear rate }\left(R_{\mathrm{W}}\right), \\
\mathrm{mg} \cdot \mathrm{m}^{-1}\end{array}$ \\
\hline \multirow{4}{*}{ Mo-free } & As-hardened & 91.2 & 0.475 \\
\hline & Single tempering ( $748 \mathrm{~K})$ & 105.6 & 0.550 \\
\hline & Double tempering (748 K) & 102.4 & 0.533 \\
\hline & Triple tempering $(748 \mathrm{~K})$ & 96.8 & 0.504 \\
\hline \multirow{4}{*}{$1 \% \mathrm{Mo}$} & As-hardened & 88.8 & 0.463 \\
\hline & Single tempering $(748 \mathrm{~K})$ & 99.2 & 0.517 \\
\hline & Double tempering (748 K) & 96.0 & 0.500 \\
\hline & Triple tempering ( $748 \mathrm{~K})$ & 89.6 & 0.467 \\
\hline \multirow{4}{*}{$2 \% \mathrm{Mo}$} & As-hardened & 89.1 & 0.458 \\
\hline & Single tempering ( $798 \mathrm{~K})$ & 97.3 & 0.504 \\
\hline & Double tempering (798 K) & 90.4 & 0.471 \\
\hline & Triple tempering (798 K) & 83.6 & 0.428 \\
\hline \multirow{4}{*}{$3 \% \mathrm{Mo}$} & As-hardened & 84.0 & 0.438 \\
\hline & Single tempering ( $798 \mathrm{~K})$ & 89.6 & 0.467 \\
\hline & Double tempering (798 K) & 87.2 & 0.454 \\
\hline & Triple tempering (798 K) & 81.6 & 0.425 \\
\hline
\end{tabular}

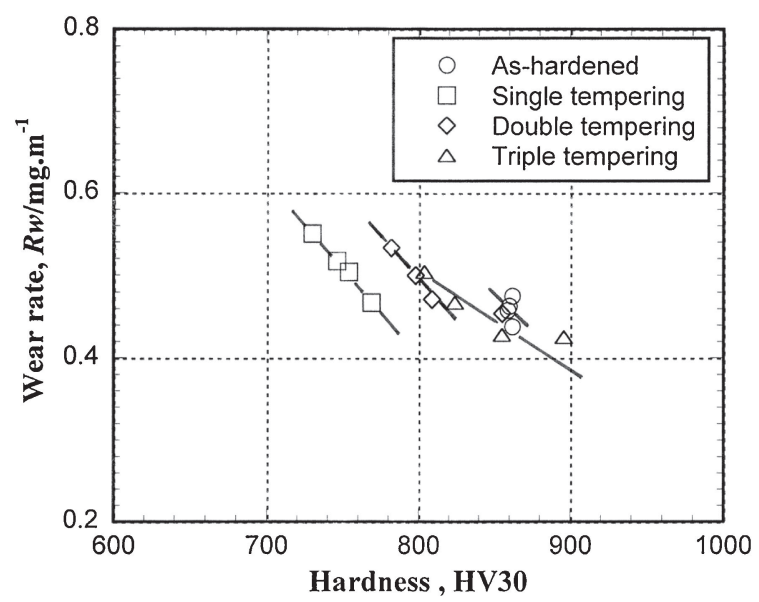

Fig. 8 Relationship between macro-hardness and wear rate $\left(R_{\mathrm{w}}\right)$ of $16 \% \mathrm{Cr}$ cast iron without and with Mo.

As-hardened: $R_{\mathrm{w}}=-1.48 \times 10^{-3} \times V_{\gamma}+0.51$

$$
\text { ( } R=0.94)
$$

Single tempering: $R_{\mathrm{w}}=-6.37 \times 10^{-3} \times V_{\gamma}+0.61$

$$
\text { ( } R=0.99)
$$

Double tempering: $R_{\mathrm{W}}=-7.58 \times 10^{-3} \times V_{\gamma}+0.58$

$$
(R=0.94)
$$

Triple tempering: $R_{\mathrm{W}}=-8.52 \times 10^{-3} \times V_{\gamma}+0.52$

$$
\text { ( } R=0.93 \text { ) }
$$

From above relations, it is found that the $R_{\mathrm{W}}$ decreases as the $V_{\gamma}$ increases. It is considered that the decrease of $R_{\mathrm{w}}$ due to a rise of $V_{\gamma}$ is might be caused by the work hardening of retained austenite. The decreasing rate of the as-hardened specimen is low because high level of austenite decreases not only the hardness but also the ratio of martensite transformation by work hardening. The $R_{\mathrm{w}}$ of the tempered specimens decreases proportionally with an increase in the $V_{\gamma}$ and the decreasing rate is almost the same. The lowest $R_{\mathrm{w}}$

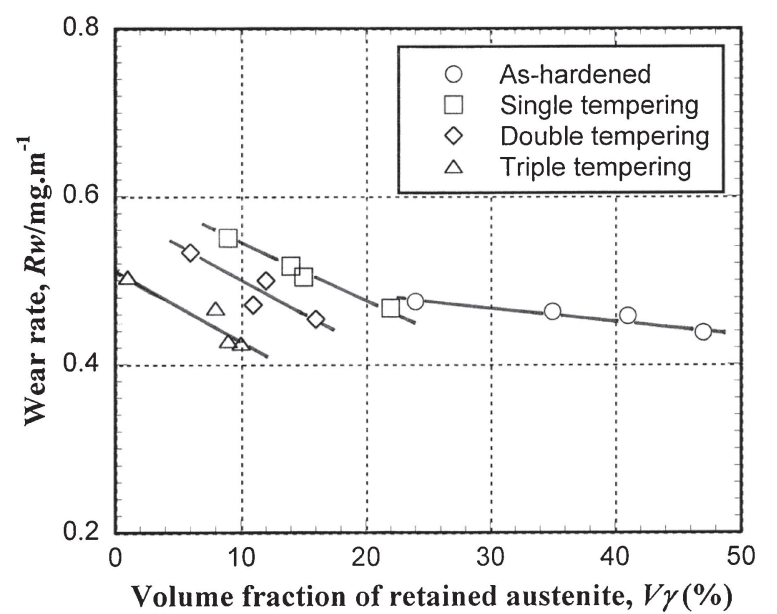

Fig. 9 Effect of volume fraction of retained austenite $\left(V_{\gamma}\right)$ on wear rate $\left(R_{\mathrm{w}}\right)$.

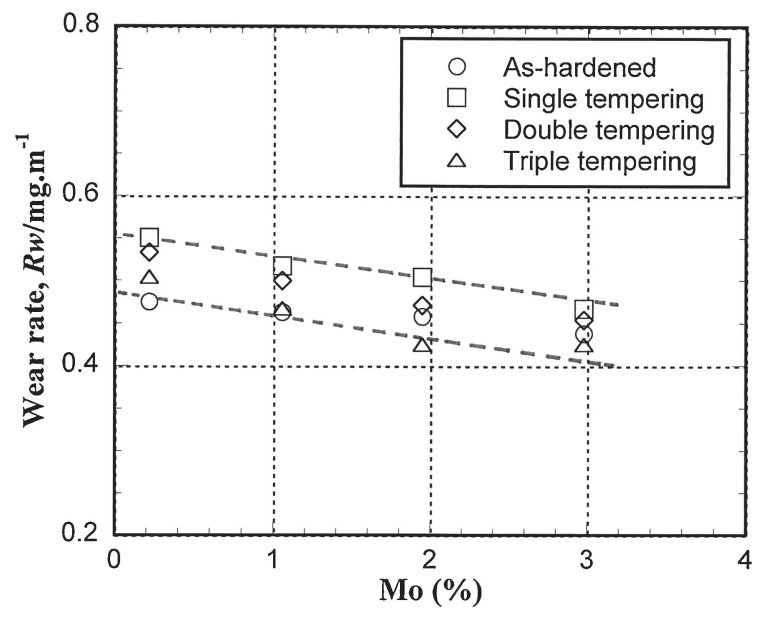

Fig. 10 Effect of Mo content of specimen on wear rate $\left(R_{\mathrm{W}}\right)$.

shifts to the low $V_{\gamma}$ side as $t_{\mathrm{N}}$ increases. Totally, the smallest $R_{\mathrm{W}}$ is obtained by the triple tempering. This is because in the triple tempering, most of retained austenite in the as-hardened state decomposed to martensite, secondary carbides and small amount of retained austenite with less than $10 \%$ remained. As a result, the highest hardness and wear resistance are obtained in the triple tempered specimens. This confirmed that even if the $V_{\gamma}$ is the same, the kind and the amount of other phases existing in the matrix affected strongly on the $R_{\mathrm{w}}$.

The effect of Mo content of the specimen on the $R_{\mathrm{w}}$ is shown in Fig. 10. The $R_{\mathrm{w}}$ decreases proportionally in a certain range as the Mo content is increased and the relation is shown as followed,

$$
R_{\mathrm{W}}=-2.50 \times 10^{-2} \times \% \mathrm{Mo}+0.48-0.56 \quad(R=0.72)
$$

This result agrees well with that of gouging abrasion test. ${ }^{14)}$ This can explain that Mo increases $V_{\gamma}$ in the as hardened state to rise the matrix hardness as well as the hardness of eutectic carbides. In the abrasion wear test, since the abrasive particles with extremely high hardness cut through both of matrix and eutectic carbides, an increase in hardness by the addition of Mo could decrease the crack propagation effectively. ${ }^{1-3)}$ It was clarified that the smallest $R_{\mathrm{W}}$ is obtained in the triple tempered specimen with $3 \%$ Mo. The reasons are as followed. 
It was reported that Mo distributed in austenite during solidification influences the solid state transformation. ${ }^{1-3,13)}$ On the other hand, the Mo, very strong carbide former, tends to form molybdenum carbide of $\mathrm{Mo}_{2} \mathrm{C}$ by a carbide reaction from martensite during tempering, ${ }^{1,3,11,13,14)}$ of which hardness is much higher compared with chromium carbide of $\mathrm{M}_{23} \mathrm{C}_{6}$. Simultaneously, Mo dissolved in the chromium carbide increases its hardness. In this experiment, such hard special carbides should precipitate secondarily in the matrix of Mo-bearing specimens during repeated tempering, the more Mo content, the more precipitated special carbides. Another reason is that a large amount of retained austenite in the as-hardened state contributes more to the precipitation of secondary carbides and post transformation of austenite to martensite. This process is accomplished mainly through the triple tempering. From Table 2, it is clear that the highest micro-hardness is obtained in the $3 \%$ Mo specimens by given the triple tempering, and this led to the highest wear resistance. From the relations in Fig. 10, it can be said that the Mo gives positive effect indirectly on the wear resistance of high chromium cast iron and the repeated tempering is also effective to the wear resistance.

The effect of the $t_{\mathrm{N}}$ on $R_{\mathrm{W}}$ is shown in Fig. 11. The $R_{\mathrm{W}}$ increases first by first tempering and then decreases as the $t_{\mathrm{N}}$ increases. In the tempered state, the $R_{\mathrm{w}}$ decreases as the $t_{\mathrm{N}}$ increases. However, the $R_{\mathrm{w}}$ of the as-hardened specimen is lower than that of the single tempered specimen. This reason is due to the difference in constitution of phases of the matrix.

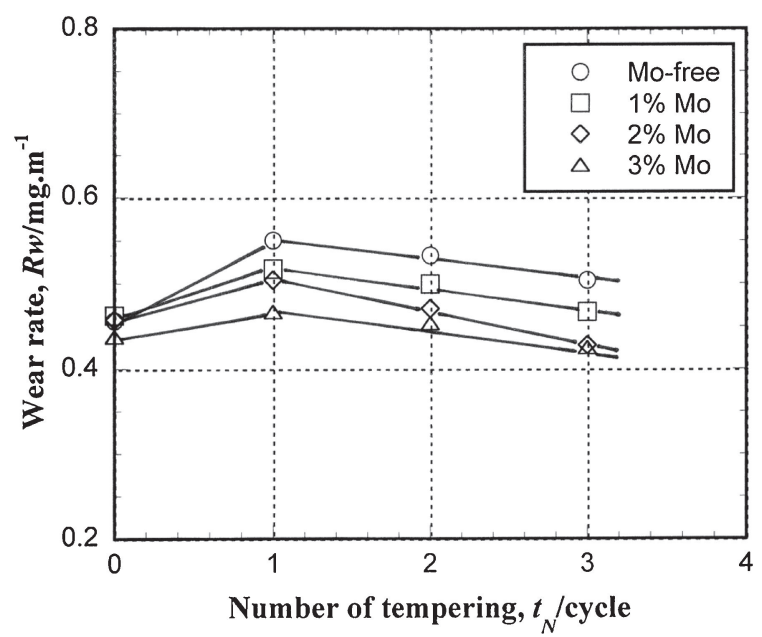

Fig. 11 Relationship between number of tempering $\left(t_{\mathrm{N}}\right)$ on wear rate $\left(R_{\mathrm{w}}\right)$.

The matrix in as-hardened specimen consists of, a large amount of austenite, martensite with high carbon and secondary carbide but the matrix in single tempered specimen is tempered martensite, secondary carbides and martensite newly transformed from retained austenite. At the same $t_{\mathrm{N}}$, the highest $R_{\mathrm{w}}$ value is obtained in Mo-free specimen and the smallest $R_{\mathrm{W}}$ is obtained in $3 \%$ Mo specimen. The reason why the $R_{\mathrm{w}}$ of the specimens with more Mo is lower could be due to the fact that the Mo-carbide precipitation in the martensite by a carbide reaction.

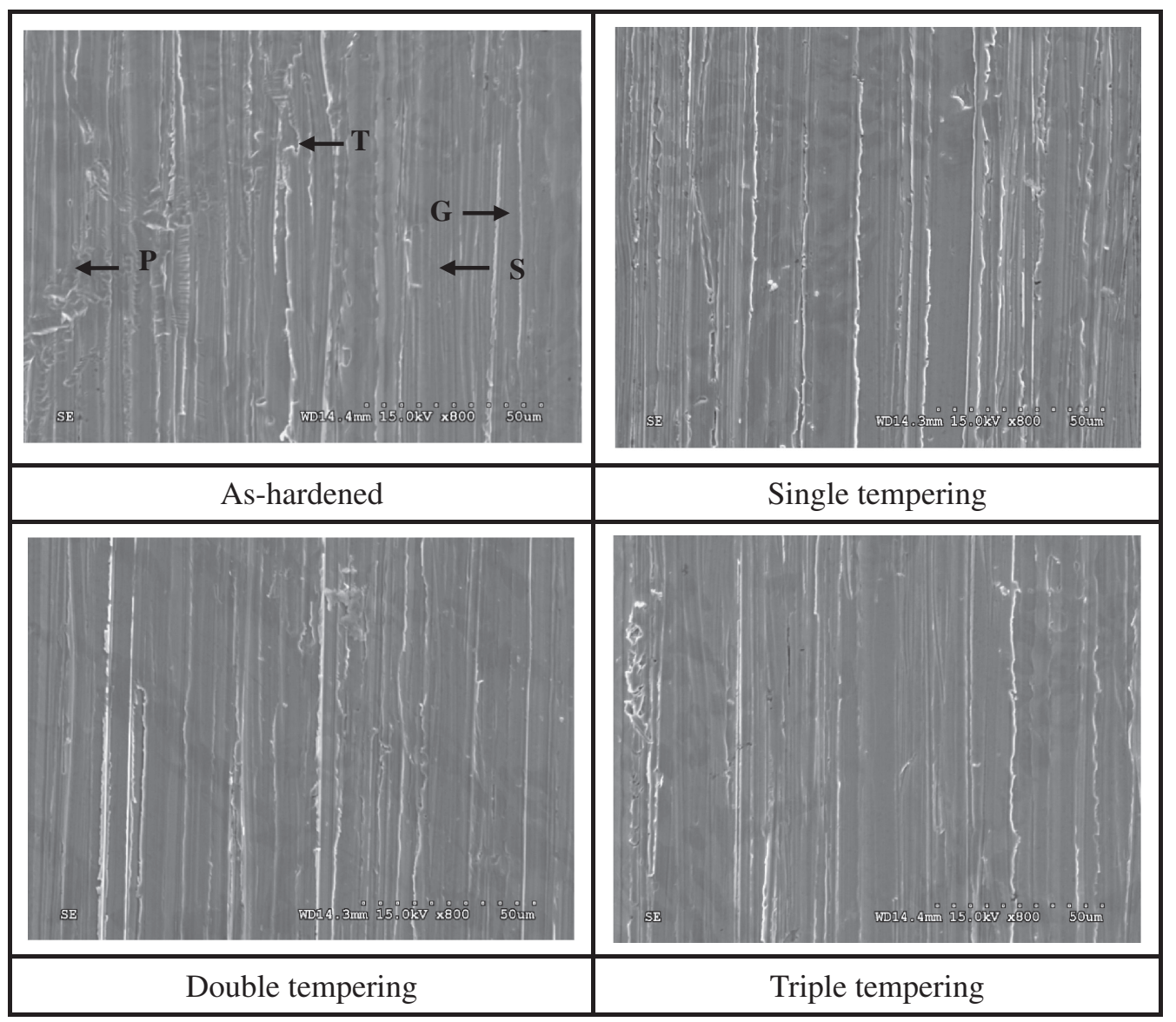

Fig. 12 SEM microphotographs of worn surfaces of $3 \%$ Mo specimen with different number of tempering $\left(t_{\mathrm{N}}\right)$. Load: $10 \mathrm{~N}(1 \mathrm{kgf})$, Wear distance: $192 \mathrm{~m}$. (S: Scratching, G: Grooving, T: Tearing and P: Pitting) 
The worn surfaces of $3 \%$ Mo specimens with different heat treatment were observed by SEM and typical microphotographs are shown in Fig. 12. On the worn surface, many wear tracks to the same direction of the wear test are observed, and they consist of grooving, pitting and scratching with small number of tearing. The pitting is usually observed in the eutectic region. The severe wear by grooving is observed in the matrix region. It is clear that the worn surface of triple tempered specimen is smoother than those of single and double tempered specimens. These appearances agree well with the results of the abrasive wear test. Here, it can be concluded that the repeated tempering can improve the wear resistance of hypoeutectic $16 \% \mathrm{Cr}$ cast iron with $\mathrm{Mo}$.

\section{Conclusions}

The wear behavior of $16 \% \mathrm{Cr}$ cast irons without and with Mo subject to repeated tempering was investigated. After annealing, the specimens were firstly hardened from $1323 \mathrm{~K}$ and then tempered at most three times. The effects of number of tempering $\left(t_{\mathrm{N}}\right)$, hardness, volume fraction of retained austenite $\left(V_{\gamma}\right)$ and Mo content on wear behavior were clarified. The following conclusions have been drawn from the experimental results and discussions.

(1) Linear relationship between wear loss and wear distance was obtained in all the specimens.

(2) When wear rate $\left(R_{\mathrm{w}}\right)$ was expressed by a slope of each straight line, the smallest $R_{\mathrm{w}}$ was obtained in the ashardened specimen for Mo-free and 1\% Mo cast irons and the triple tempered specimen in the $2 \%$ and $3 \% \mathrm{Mo}$ cast irons. The highest $R_{\mathrm{w}}$ was obtained in the single tempered specimen regardless of Mo content of the cast iron.

(3) The $R_{\mathrm{w}}$ decreased as the macro-hardness, $V_{\gamma}$ and Mo content were increased.
(4) The $R_{\mathrm{w}}$ increased first and then decreased as $t_{\mathrm{N}}$ increased. The highest wear resistance was obtained in the $3 \%$ Mo specimen with triple tempering.

\section{Acknowledgements}

The authors wish to express appreciation to Thailand Research Funding and Panaplus Company for research funding and to the Faculty of Engineering, Mahasarakham University for use of the experimental devices.

\section{REFERENCES}

1) G. Laird, R. Gungdlach and K. Rohring: Abrasive-Resistance Cast Iron Handbook, (The American Foundry Society, USA, 2000).

2) M. Ikeda, T. Umeda, C. Tong, T. Suzuki, N. Niwa and O. Kato: ISIJ Int. 32 (1992) 1157-1162.

3) C. P. Tabrett, I. R. Sare and M. R. Ghomashchi: Int. Mater. Rev. 41 (1996) 59-82.

4) K. Zum Gahr and D. V. Doane: Metall. Mater. Trans. A 11 (1980) 613620.

5) Y. Matsubara, K. Ogi and K. Matsuda: AFS Trans. 89 (1981) 183-196.

6) S. Inthidech, P. Aungsupaitoon, P. Sricharoenchai and Y. Matsubara: Int. J. Cast Metals Res. 23 (2010) 164-172.

7) O. N. Dogan and J. A. Hawk: AFS Trans. 106 (1998) 625-631.

8) S. Inthidech, P. Sricharoenchai and Y. Matsubara: Mater. Trans. 47 (2006) 72-81.

9) S. Inthidech, K. Boonmak, P. Sricharoenchai, N. Sasaguri and Y. Matsubara: Mater. Trans. 51 (2010) 1264-1271.

10) S. Inthidech, P. Sricharoenchai, N. Sasaguri and Y. Matsubara: AFS Trans. 112 (2004) 899-910.

11) I. R. Sare and B. K. Arnold: Metall. Mater. Trans. A 26 (1995) 357-370.

12) P. Sricharoenchai, S. Inthidech, N. Sasaguri and Y. Matsubara: AFS Trans. 112 (2004) 911-923.

13) S. Inthidech, P. Sricharoenchai and Y. Matsubara: Mater. Trans. 49 (2008) 2322-2330.

14) I. R. Sare and B. K. Arnold: Metall. Mater. Trans. A 26 (1995) 17851793.

15) C. Kim: J. Heat Treating 1 (1979) 43-51. 